\title{
Resiliência e Vulnerabilidade nos sistemas ecológicos: Envelhecimento e políticas públicas
}

\author{
Lara Monteiro Schuck* \\ Clarissa De Antoni \\ Universidade Federal de Ciências da Saúde de Porto Alegre, Porto Alegre, RS, Brasil
}

\begin{abstract}
RESUMO - O envelhecimento da população brasileira leva ao questionamento do papel dos serviços de saúde e das políticas públicas, principalmente no que se refere ao cuidado do idoso dependente e sua família. Realizou-se um estudo de caso com uma família investigando fatores de risco e de proteção presentes nos sistemas ecológicos: meso-, exo- e macrossistema de um idoso dependente fisicamente, por meio de entrevista semiestruturada, Entrevista Familiar Estruturada, Inventário de Percepção do Suporte Familiar, observação naturalística, genograma e pesquisa documental. Foram identificados diversos fatores de risco - como a falta de apoio social e o ageísmo - e fatores de proteção - como a oferta de cuidados domiciliares por uma equipe de saúde e a presença de legislação condizente com as mudanças populacionais. Percebe-se a importância desses indicadores no processo de resiliência familiar.
\end{abstract}

Palavras-chave: envelhecimento, resiliência, políticas públicas.

\section{Resilience and vulnerability in ecological systems: Aging and public policies}

\begin{abstract}
The aging of the Brazilian population questions the role of health services and public policies, especially the care of dependent elderly and their families. We conducted a family case study investigating risk and protective factors in ecological systems (meso-, exo- and macrosystem) present in a physically dependent elderly, through semi-structured interview, the Structured Family Interview, Perceived Family Support Inventory, naturalistic observation, documentary research and a genogram. We identified various risk factors - as lack of social support and ageism - and protective factors - as home care provided by a health team, as well as legislation consistent with population changes. The importance of these indicators for the process of family resilience is stressed.
\end{abstract}

Keywords: old age, resilience, public policies.

Uma tendência crescente nos países em desenvolvimento é o envelhecimento de sua população. Segundo censo realizado pelo Instituto Brasileiro de Geografia e Estatística (IBGE; 2011), a população acima de 60 anos no Brasil representa $10,8 \%$ da população atual e mostra um crescimento em relação ao censo anterior (realizado em 2000, quando essa população representava 8,5\%). Esses dados apontam que a qualidade de vida dos idosos deve ser objeto de atenção, visto que a tendência é o aumento gradativo destes números (Moreira \& Caldas, 2007; Nardi \& Oliveira, 2008; Tier et al., 2006). Outras tendências da família atual são o número cada vez menor de filhos, e o fato de que geralmente a maioria dos membros trabalha fora de casa e contribui economicamente para a renda familiar (Augusto, Da Silva, \& Ventura, 2009).

Com a longevidade avançando, a probabilidade de se terem idosos com doenças crônicas é cada vez maior (Lavinsky \& Vieira, 2004; Mazza \& Lefévre, 2005), sendo que, no Brasil, quem assume os cuidados destes idosos, em sua maioria, são seus familiares (Moreira \& Caldas, 2007; Willig, Lenardt, \& Méier, 2012). Além disso, como apontam Neri et al. (2013), as questões relacionadas à fragilidade do

* Endereço para correspondência: Rua Sarmento Leite, 245/ sala 207, Porto Alegre, Rio Grande do Sul (RS), CEP 90050-170.

E-mail: s.mlara@hotmail.com idoso com 60 anos ou mais estão muitas vezes condicionadas à pobreza, à baixa escolaridade e à limitada rede de apoio, formada principalmente por familiares mais próximos (Alvarenga, 2011). A própria Política Nacional do Idoso (PNI) revela que $98 \%$ dos cuidadores de idosos com algum grau de dependência são os membros familiares ou aqueles que têm maior proximidade afetiva com o idoso (Augusto, Da Silva, \& Ventura, 2009; Silveira, Caldas, \& Féres-Carneiro, 2006; Pereira et al., 2013).

Somando-se esses dados à vida cada vez mais multitarefada dos membros da família, pode-se prever que, no momento em que os membros idosos tornam-se dependentes fisicamente por não poderem mais desenvolver tarefas cotidianas, como alimentar-se, banhar-se e, até mesmo deslocarem-se sozinhos, essa situação pode gerar impasses e angústias frente à dificuldade de prover-lhes cuidado integral (Tavares et al., 2012). Por outro lado, a institucionalização é, muitas vezes, dispendiosa e malvista, pela questão cultural que associa o acolhimento asilar ao abandono familiar. Segundo Augusto et al. (2009), o processo de cuidado familiar sempre existiu, variando na sua maneira (presença de mais familiares, por exemplo). Entretanto, esse papel só tem sido legitimado como tal mais recentemente.

Diversos estudos têm sido realizados na temática do envelhecimento com dependência (Barbosa, Oliveira, \& 
Figueiredo, 2012; Diogo, Ceolim, \& Cintra, 2005 ; Sebastião \& Albuquerque, 2011; Tavares et al, 2012 ; Vieira, Nobre, Bastos, \& Tavares, 2012;). No entanto, há carência de estudos que analisem esse fenômeno de maneira articulada entre a família e as políticas públicas de saúde destinadas aos idosos. Por meio do olhar direcionado aos atores sociais envolvidos, pode-se problematizar a forma como as políticas públicas se fazem presentes no cotidiano dos familiares que vivem essa situação, mesmo que eles não as percebam.

Este estudo tem como objetivo compreender os processos de resiliência e vulnerabilidade frente à situação de cuidado de um idoso acamado e a articulação das políticas públicas vigentes em saúde para idosos no Brasil. Para tanto, são analisados os contextos ecológicos nos quais o idoso está inserido (meso-, exo- e macrossistema) por meio da Teoria Bioecológica do Desenvolvimento Humano (TBDH). Esses contextos podem ser promotores de resiliência ou potencializar ainda mais a situação de vulnerabilidade na qual o idoso vive.

\section{As Políticas Públicas para o Idoso no Brasil}

O estudo da temática do envelhecimento na sociedade brasileira assim como as políticas públicas para idosos são relativamente recentes. A maneira como a sociedade compreende o envelhecimento e as ações direcionadas a esse segmento populacional, na forma de políticas públicas, podem influenciar e até determinar a maneira como os subsistemas, como a família e a equipe de saúde, por exemplo, vão lidar com a situação de ter um idoso dependente sob seus cuidados. Os estudos de Camarano e Pasinato (2004) e de Rodrigues (2001) apresentam revisões bastante abrangentes sobre projetos e ações que foram desenvolvidos ao longo de décadas e que subsidiaram, de alguma forma, a atual PNI. A preocupação governamental com o idoso intensificou-se na década de 1970, período em que o crescimento desse segmento populacional e as transformações familiares tornaram-se realidades cada vez mais comuns. No final da década de 1980, a Constituição Brasileira determinou às famílias a responsabilidade com os membros idosos, promovendo sua desinstitucionalização (Willig et al., 2012). A atual PNI, Lei $\mathrm{n}^{\circ} 8.842$, de janeiro de 1994, elaborada a partir da luta pela conquista de direitos dessa população, que tem se tornado cada vez mais numerosa no Brasil, tem por objetivos principais a promoção de autonomia e a participação ativa e efetiva dos idosos na sociedade (PNI, 2010; Rodrigues, 2001). A PNI incorpora uma série de decretos que visam assegurar os direitos sociais dos idosos e engloba ações dos diferentes setores sociais que devem envolver-se na elaboração e implementação de políticas públicas voltadas a esse segmento. A PNI tem diversos preceitos. Entre eles, destaca-se a priorização do atendimento de idosos pelas famílias em detrimento do acolhimento asilar (ressaltando-se a importância de capacitação dos cuidadores informais, tanto familiares como pessoas próximas ao idoso), bem como capacitação e suporte técnico e emocional para essas famílias, providos pelas equipes de saúde. Constitui-se, portanto, uma Política intersetorial e que torna a sociedade, o
Estado e a família corresponsáveis pelo cumprimento desses preceitos (PNI, 2010).

Ao se pensar no envelhecimento, no entanto, deve-se ter atenção ao fato de que é uma faixa etária que se inicia aos 60 anos e compreende uma margem de 30 a 40 anos, sendo, portanto, composta por uma população extremamente heterogênea entre si (Camarano, 2006). Além de questões desenvolvimentais, físicas, socioeconômicas e culturais, existe o fato de que a trajetória de vida de cada ser humano influencia o seu processo de envelhecimento, bem como em que grau o idoso dependerá de políticas assistenciais e de saúde (Camarano, 2006). Segundo Willig et al. (2012), as políticas voltadas ao idoso, consolidadas na PNI, no Estatuto do Idoso e na Política Nacional de Saúde da População Idosa (PNSPI), estão bem estruturadas e consonantes com outras legislações internacionais. No entanto, suas práticas estão defasadas, a exemplo do que apontam Tavares e colaboradores (2012), em relação a dificuldades existentes na falta de programas de seguridade social voltados aos idosos que se tornam dependentes, o que indica que, apesar de ser uma situação socialmente reconhecida, a efetivação das políticas públicas ainda é incipiente.

\section{A Compreensão do Envelhecimento com Dependência a partir da Teoria Bioecológica do Desenvolvimento Humano (TBDH)}

A TBDH permite a análise dos fatores que influenciam, de alguma forma, o desenvolvimento humano, privilegiando o desenvolvimento no contexto e levando em conta diferentes dimensões interrelacionadas: o Processo, a Pessoa, o Contexto e o Tempo (PPCT; Brofenbrenner, 2011). A dimensão Pessoa envolve as características biopsicossociais de cada sujeito analisado; a dimensão Processo diz respeito às interpretações em relação às interações estabelecidas nos ambientes; já o Contexto compreende a interação de quatro níveis ambientais descritos a seguir e o tempo tem relação com a passagem de eventos socio-históricos e cotidianos na vida da pessoa. Em relação ao contexto, a relação cuidador-idoso influencia e é influenciada por diferentes sistemas ecológicos em que vivem as pessoas (Cassol \& De Antoni, 2011; De Antoni, Barone, \& Koller, 2011; Poletto \& Koller, 2011; Schuck \& De Antoni, 2014). Pode-se analisar tais fatores em diferentes níveis: o microssistema familiar, que corresponde ao que ocorre na família propriamente dita; o mesossistema, que corresponde às trocas que essa família realiza com outros microssistemas, como a Unidade Básica de Saúde, escolas, local de trabalho etc.; o exossistema, que corresponde às políticas e programas que interferem indiretamente no microssistema familiar e nas ações dos membros; e o macrossistema, que envolve padrões culturais e crenças da sociedade em que a família vive, os quais perpassam todos os outros sistemas (Brofenbrenner, 2011).

Em todos os contextos em que vive o Eu Ecológico (ser humano ou grupo familiar em desenvolvimento) há fatores de risco e de proteção ativos, funcionando de maneira dinâmica e influenciando os processos familiares em seu desenvolvimento. Segundo De Antoni e Koller (2010) o termo risco tem sido utilizado para denominar fatores ou 
situações potencialmente estressoras, que possam predispor a um desfecho negativo ou indesejado; já o termo proteção refere-se a fatores que poderão defender ou fortalecer a pessoa frente a uma situação de vulnerabilidade.

Dessa forma, os fatores de risco e de proteção são processos, e não eventos estáticos, e devem ser compreendidos de acordo com a situação e o contexto, pois, dependendo das suas implicações nas relações e os resultados específicos de cada situação, alguns fatores podem constituir-se tanto como risco quanto como proteção. Se, frente a determinado(s) fator(es) de risco, uma pessoa ou um grupo não consegue utilizar-se de estratégias adequadas de enfrentamento, pode-se identificar uma situação de vulnerabilidade naquele momento. No entanto, se consegue enfrentar tal(is) fator(es) de maneira adaptativa, ocorrendo um aprendizado com essa situação, esse processo é denominado resiliência (De Antoni \& Koller, 2010). A resiliência se refere a processos que operam na presença de fatores de risco e evidenciam a potencialidade dos mecanismos de proteção realmente exercerem a proteção frente a essas adversidades (Poletto \& Koller, 2011).

Segundo a conceituação de resiliência como um processo, esta seria um fenômeno complexo que se constrói na interrelação dos múltiplos contextos com os quais o ser humano ou o microssistema familiar interage de maneira direta ou indireta (Silva, Lacharité, Silva, Lunardi, \& Lunardi Filho, 2009). Ao se considerarem, portanto, os processos de resiliência de um microssistema familiar, deve-se observar o processo interacional com os demais sistemas ecológicos nos quais a família está inserida, ao longo do tempo, e que fortalecem tanto a família quanto seus indivíduos (Silva et al., 2009).

Portanto, a TBDH pode auxiliar em uma compreensão sistêmica e integrada da situação de envelhecimento com dependência, visto ser esta uma situação cujo manejo adequado depende de todos os sistemas descritos anteriormente. Portanto neste estudo, o foco de análise será o mesossistema, o exossistema e o macrossistema de uma família com um idoso em situação de dependência.

\section{Método}

Trata-se de um estudo de caso exploratório, qualitativo e transversal. O caso descrito neste estudo foi selecionado por conveniência, por meio da busca de prontuários em uma Unidade Básica de Saúde (UBS) de Porto Alegre (RS), a qual consentiu em colaborar com o estudo. A família foi selecionada com base em alguns critérios: ter um idoso dependente fisicamente, mas com a cognição preservada, para que pudesse responder aos instrumentos, e ter um familiar como cuidador principal.

Foram revisados todos os prontuários inseridos no Programa de Atenção Domiciliar (PAD), estratégia do Sistema Único de Saúde (SUS) de desospitalização e referenciamento para a Atenção Primária à Saúde, após a alta hospitalar, em que o usuário fica sob os cuidados de uma equipe multidisciplinar da UBS em que está cadastrado, realizando consultas através de Visitas Domiciliares (VDs), visando à promoção da autonomia do cuidado, já que não pode deslocar-se. Após o contato e consentimento dos familiares, foram realizadas visitas sistemáticas, nas quais foram aplicados os seguintes instrumentos: (a) uma entrevista semiestruturada, adaptada para cada um dos participantes e elaborada pelas pesquisadoras, que avalia a situação de cuidado e os sentimentos gerados por ela; (b) a Entrevista Familiar Estruturada (EFE; Féres-Carneiro, 1997), que investiga dimensões relativas à comunicação, regras, papéis, liderança, manifestações de agressividade, afeição física, interação conjugal, individualização, integração, autoestima e saúde emocional (Teodoro, 2012); e (c) o Inventário de Percepção do Suporte Familiar (IPSF; Baptista, 2007), respondido apenas pela cuidadora, que investiga três características do suporte familiar, intituladas Afetivo - Consistente, Adaptação Familiar e Autonomia (Teodoro, 2012). Foram realizados, ainda, uma observação naturalística (inserção ecológica) do contexto familiar, o estudo do genograma e uma pesquisa documental no prontuário familiar, para busca de dados de saúde e características do acompanhamento familiar.

A família selecionada possui um idoso em situação de dependência por decorrência de Acidente Vascular Cerebral, e sua filha tem o papel de cuidadora, o que corrobora a tendência exposta na literatura (Pereira et al., 2013). O idoso e sua filha foram entrevistados separadamente e em conjunto.

\section{Análise dos Dados}

A partir do exposto acima e da triangulação dos dados coletados por meio dos instrumentos utilizados, relacionando-os com as políticas públicas para idosos e com a literatura disponível sobre a temática, foram identificados fatores de risco e de proteção que perpassam os diferentes sistemas em que seus membros se inserem. Entretanto, neste estudo, o foco de análise são os fatores de risco e proteção no mesossistema (relação e cuidados da UBS com a família); exossistema (impacto das políticas públicas na realidade familiar); e macrossistema (crenças e padrões culturais presentes na realidade familiar). Esses fatores relacionavam-se à situação de dependência, podendo configurar-se de risco, quando dificultavam, em algum nível, a provisão de cuidados adequados ao idoso. Da mesma forma, podiam relacionar-se ao processo de resiliência familiar quando facilitavam a provisão de cuidados adequados ao idoso e contribuíam para a manutenção da saúde física e emocional dos membros familiares. Esses fatores não são estáticos, podendo ora ser considerados de risco, ora de proteção, dependendo das variáveis associadas. Por estarem interligados e em relação, os fatores de proteção e de risco foram analisados dinamicamente. No entanto, esses também são apresentados de maneira didática, agrupados em fatores de análise e divididos de acordo com o que concerne a cada sistema. As análises sobre o eu ecológico do idoso, o eu ecológico da cuidadora e o microssistema familiar não serão expostas neste estudo, pois já foram publicadas em Schuck e De Antoni (2014). O foco deste estudo são o mesossistema, exossistema e macrossistema, em relação ao Cuidado (refere-se aos cuidados prestados tanto pela família quanto pela equipe de saúde ao idoso), 
às Variáveis Sociais (refere-se às variáveis sociais que se fazem presentes no cotidiano familiar e nos cuidados com o idoso), às Variáveis de Saúde (refere-se às variáveis de saúde que se fazem presentes no cotidiano familiar e nos cuidados com o idoso), e à PNI (refere-se à maneira como esta se faz presente no cotidiano familiar e nos cuidados com o idoso). Esses fatores foram integrados ao modelo PPCT da TBDH, para uma compreensão dinâmica e ecológica do fenômeno e dos fatores de risco e de proteção presentes. O modelo de análise utilizado foi proposto por Koller e De Antoni (2004), no qual são apresentados os fatores de risco e de proteção nos diferentes contextos ecológicos.
Este estudo seguiu todas as recomendações éticas para a realização de pesquisas com seres humanos, de acordo com as orientações da Resolução 196/1996 do Conselho Nacional de Saúde. Todos os participantes assinaram Termo de Consentimento Livre e Esclarecido (TCLE) e o presente estudo obteve aprovação do Comitê de Ética em Pesquisa da Universidade Federal de Ciência da Saúde de Porto Alegre (UFCSPA). Para preservar a identidade dos participantes, optou-se por apresentá-los pela letra inicial de seu papel familiar em relação ao Idoso (I): Filha (F), Esposa (E), Genro (G), Netos (N1 e N2).

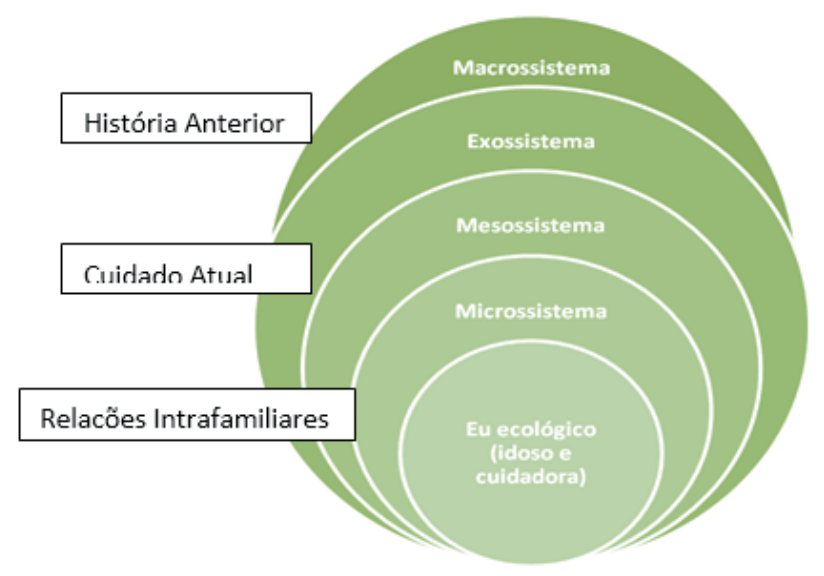

Autopercepção e Positividade

Variáveis Sociais e de Saúde

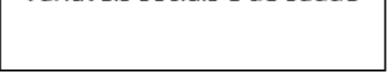

PNI

Figura 1. Modelo de Análise dos Dados

\section{Resultados e Discussão}

\section{Caracterização e Breve Histórico da Família}

A família era formada pelo idoso, I (61 anos), sua esposa, E (63 anos), sua filha, F (26 anos), a cuidadora familiar principal, seu marido, G (26 anos), e seus dois filhos, N1 (11 anos) e N2 (1 ano). $\mathbf{F}$ foi adotada pelo casal quando tinha três dias de vida. $\mathrm{O}$ idoso aparentava fragilidade física devido aos Acidentes Vasculares Cerebrais (AVCs) sofridos dois anos antes deste estudo. No entanto, não aparentava estar com o peso abaixo do esperado.

Moram na casa I, E e N1. Os demais familiares frequentam todos os dias a casa de I. F é quem fica responsável por todos os cuidados com o pai, até a chegada de E em casa após o trabalho, à noite. $\mathbf{F}$ parou de trabalhar e de estudar em função do AVC do pai, ficando responsável integralmente pelos cuidados com o pai e com a casa. I trabalhava e, em 2010, quando teve o AVC ficou internado por alguns meses e lá sofreu outros dois AVCs, que o incapacitaram fisicamente, levando a uma hemiparesia do lado esquerdo.
Devido ao agravamento do quadro, $\mathbf{F}$ realizou mudanças significativas em sua vida para cuidar do seu pai: "eu trabalhava, eu fazia faculdade e dai tive que parar de uma hora pra outra. Ai a gente veio morar, teve que vir pra mais perto dele". Desde a ocorrência do primeiro $\mathrm{AVC}$, a equipe de saúde da UBS passou a acompanhar com frequência a situação da família, principalmente do idoso. Depois de seis meses, I teve que retornar ao hospital para amputação do pé esquerdo, ocasionada por uma infecção hospitalar, identificada pela equipe de saúde. Em decorrência dos AVCs, a família foi incluída no PAD, e a equipe passou a fazer VDs frequentemente, para acompanhamento da situação. Ainda, a UBS viabilizou serviços como fisioterapia e o recebimento do Benefício de Prestação Continuada (BPC) ao idoso.

\section{Fatores de Proteção e de Risco}

Diversos fatores de proteção e de risco foram encontrados no meso, exo e macrossistema para análise dos processos de resiliência e vulnerabilidade no microssistema familiar. As tabelas abaixo mostram os fatores de risco e de proteção. 
Tabela 1

Fatores de Proteção Relevantes para Avaliação da Resiliência no Contexto do Envelhecimento com Dependência na Família Investigada

\begin{tabular}{|c|c|c|c|}
\hline Indicador & Mesossistema & Exossistema & Macrossistema \\
\hline $\begin{array}{l}\text { Cuidado (cuidado provido ao } \\
\text { idoso, seja da família ou da } \\
\text { Unidade de Saúde) }\end{array}$ & $\begin{array}{l}\text { Existência de uma equipe de } \\
\text { referência } \\
\text { Boa relação entre equipe de } \\
\text { saúde e família } \\
\text { Equipe de saúde percebe } \\
\text { positivamente o cuidado } \\
\text { familiar }\end{array}$ & $\begin{array}{l}\text { Inserção no PAD } \\
\text { Estruturação do SUS na APS }\end{array}$ & \\
\hline $\begin{array}{l}\text { Variáveis Sociais (relações } \\
\text { estabelecidas para além do } \\
\text { microssistema familiar) }\end{array}$ & $\begin{array}{l}\text { Pastor da igreja busca o idoso } \\
\text { toda semana para ir à missa }\end{array}$ & $\begin{array}{l}\text { PNI preconiza a importância } \\
\text { da convivência comunitária do } \\
\text { idoso }\end{array}$ & \\
\hline $\begin{array}{l}\text { Variáveis de Saúde (acesso } \\
\text { da família aos serviços de } \\
\text { saúde, situação de saúde dos } \\
\text { familiares) }\end{array}$ & $\begin{array}{l}\text { Cadastro da família na UBS do } \\
\text { território } \\
\text { Percepção positiva da APS }\end{array}$ & $\begin{array}{l}\text { Estruturação do SUS } \\
\text { PAD } \\
\text { Melhora dos fatores de saúde } \\
\text { brasileiros }\end{array}$ & \\
\hline $\begin{array}{l}\text { Política Nacional do Idoso } \\
\text { (repercussões da PNI nos } \\
\text { diferentes sistemas em que a } \\
\text { família está inserida) }\end{array}$ & $\begin{array}{l}\text { UBS como elo entre usuários e } \\
\text { políticas - articulação realizada } \\
\text { para recebimento do BPC }\end{array}$ & $\begin{array}{l}\text { Políticas e leis: Estatuto do } \\
\text { Idoso; Constituição de 1988; } \\
\text { Pacto pela Vida - SUS; } \\
\text { Conselho Nacional do Idoso }\end{array}$ & $\begin{array}{l}\text { Crença na necessidade da } \\
\text { manutenção da inserção dos } \\
\text { idosos na sociedade }\end{array}$ \\
\hline
\end{tabular}

Adaptado de Koller \& De Antoni (2004)

Tabela 2

Fatores de Risco Relevantes para Avaliação da Resiliência no Contexto do Envelhecimento com Dependência na Família Investigada

\begin{tabular}{|c|c|c|c|}
\hline Indicador & Mesossistema & Exossistema & Macrossistema \\
\hline Cuidado & $\begin{array}{l}\text { Percepção negativa do nível } \\
\text { terciário de atenção à saúde } \\
\text { Falta de apoio social formal e } \\
\text { informal } \\
\text { Personalização da atuação } \\
\text { profissional } \\
\text { Atenção da UBS centrada nos } \\
\text { cuidados clínicos }\end{array}$ & $\begin{array}{l}\text { Políticas e seus recursos não } \\
\text { estão acessíveis facilmente } \\
\text { Desresponsabilização do Estado } \\
\text { e de seus dispositivos } \\
\text { Falta de programas específicos } \\
\text { de apoio a familiares } \\
\text { cuidadores }\end{array}$ & $\begin{array}{l}\text { Crença de que a família deve } \\
\text { cuidar dos seus idosos } \\
\text { Vulnerabilidade social e } \\
\text { econômica familiar }\end{array}$ \\
\hline Variáveis Sociais & $\begin{array}{l}\text { Falta de apoio formal e } \\
\text { informal }\end{array}$ & & $\begin{array}{l}\text { Crença que o trabalho esta } \\
\text { vinculado ao pertencimento } \\
\text { social por meio do que se } \\
\text { produz. }\end{array}$ \\
\hline Variáveis de Saúde & $\begin{array}{l}\text { Escassez de acompanhamento } \\
\text { atualmente } \\
\text { Personalização do cuidado }\end{array}$ & $\begin{array}{l}\text { Políticas públicas pouco } \\
\text { visíveis neste contexto }\end{array}$ & $\begin{array}{l}\text { Saúde configurada no modelo } \\
\text { biomédico, falta de prevenção } \\
\text { primária } \\
\text { Saúde regida pela ideologia } \\
\text { neoliberal e privativista }\end{array}$ \\
\hline Política Nacional do Idoso & & $\begin{array}{l}\text { Necessidade de criação de } \\
\text { programas específicos de apoio } \\
\text { a familiares cuidadores } \\
\text { Desresponsabilização dos } \\
\text { setores sociais } \\
\text { Políticas públicas pouco } \\
\text { visíveis }\end{array}$ & $\begin{array}{l}\text { Cultura brasileira: familiares } \\
\text { têm a obrigação de cuidar dos } \\
\text { seus idosos }\end{array}$ \\
\hline
\end{tabular}

Adaptado de Koller \& De Antoni (2004) 


\section{Cuidado}

Com relação a essa situação de cuidado familiar que se configurou após a ocorrência dos AVCs, destacam-se como fatores de proteção o fato de o idoso sentir-se bem cuidado pela filha e pela equipe de saúde da UBS: "Melhor é impossível" (I); a escolaridade de $\mathbf{F}$, que permite a ela compreender a condição clínica de I e os cuidados repassados pela equipe de saúde (Pereira et al., 2013); e a própria lógica do PAD, a qual tem muito a contribuir para o desempenho do cuidado familiar, garantindo a presença regular de uma equipe de saúde familiarizada com a história familiar e com o território em que vivem. A isso, relaciona-se a estruturação do SUS, através da territorialização do cuidado, que permite tal proximidade. Essa equipe de saúde está atenta ao cuidado prestado pela família e percebe que estão relativamente bem organizados e são mais autônomos em relação ao cuidado. Sua presença foi importante nos cuidados logo após o AVC, mantendo VDs frequentes (semanalmente/quinzenalmente) até 12 meses após a última internação. Há uma boa relação entre a equipe e a família, e esta a percebe como importante: "Ah, eu acho bem interessante, pra ele, assim, porque [...] por exemplo, assim, agora saiu um negócio nele, a gente não sabe o que fazer, né, eles já tem, já vem, já sabem uma medicação, né. Eu acho bem importante" (F).

Um fator de risco foi a transferência do cuidado do idoso à família, pela PNI e pela Constituição de 1988, o que, embora constitua um avanço, desresponsabiliza o Estado, a sociedade e seus dispositivos, sobrecarregando o microssistema familiar (Areosa \& Areosa, 2008; Vieira \& Fialho, 2010). F está sobrecarregada, sente-se estressada e frustrada, não percebendo aspectos positivos em ser cuidadora. Possivelmente, tais sentimentos têm relação com o fato de ter abandonado o curso superior e o emprego para cuidar do pai, além de não ter apoio social nenhum fora do microssistema familiar:

“...sempre gostei de trabalhar, porque pra mim é complicado né, mas claro, eu fico porque é meu pai, porque se não... Não seria essa a minha escolha, de um dia virar cuidadora. Eu gostaria de trabalhar fora, sabe. [...] Só pelo fato de eu ter que ter parado com os meus estudos, ter que, né, me centralizar mais neles né, ajudar ele né, a mãe". (F)

Os cuidadores familiares comumente se veem forçados a retirar-se do mercado de trabalho por não conseguir dar conta das duas demandas (Sebastião \& Albuquerque, 2011). Parece haver, por parte da equipe de saúde, falta de percepção da necessidade de apoio emocional, já que esta centra seus cuidados nos aspectos clínicos, não aparentando ter auxiliado a família a reorganizar-se para buscar apoio social informal (Tavares et al., 2012; Vieira et al., 2012). Por outro lado, a cuidadora costuma recusar auxílios que são oferecidos (apoio psicológico e curso de cuidador). Além disso, parece haver uma falta de programas específicos de apoio a familiares cuidadores, que promovam suporte emocional, mobilização de recursos, capacidade de resolução de problemas e conhecimento sobre o processo de envelhecimento (Vieira et al., 2012), algo que é preconizado pela PNI. Conjuntamente com esses fatores, estão a crença e expectativa sociais de que é a família que deve cuidar dos seus idosos e a própria vulnerabilidade econômica e social dessa família. Isso impossibilita a busca de recursos mais especializados ou a adaptação da própria residência da maneira ideal.

\section{Variáveis Sociais e de Saúde}

Percebe-se a presença de fatores protetivos relacionados a algumas variáveis sociais e de saúde: o idoso frequenta a igreja semanalmente, e o pastor vem buscá-lo em casa. Além disso, ele visita seus familiares, sendo levado pela filha e pelo genro, algo que o alegra. São momentos em que ele pode deslocar seu foco da sua própria doença para atividades sociais. A própria PNI preconiza a importância da convivência comunitária do idoso. Todos os membros familiares são cadastrados na UBS, o que é possível com a universalização da saúde preconizada pelo SUS, e, mesmo não referindo maiores problemas, a equipe pode acompanhálos de maneira longitudinal. A existência do PAD também pode ser destacada, assim como a própria melhora dos fatores de saúde brasileiros (Camarano \& Pasinato, 2004; Fernandez \& Santos, 2010; Moreira \& Caldas, 2007). A própria PNI é um indicador protetivo tanto para I quanto para que sua família desempenhe um cuidado melhor amparado. Nessa configuração, a UBS atua como articuladora entre as políticas públicas e os usuários. Um exemplo disso é a viabilização do recebimento do Benefício de Prestação Continuada (BPC) ao idoso, realizada via UBS, o que contribui para a renda familiar de $\mathbf{I}$.

Como fatores de risco, destacam-se a impossibilidade de I trabalhar no mercado de trabalho formal, da maneira como o fazia anteriormente aos AVCs, algo que era muito significativo para ele. Ele sente-se atualmente como um inútil, e pode-se relacionar a isso o fato de que, em nossa cultura, o trabalho envolve um senso de pertencimento social, que é constitutivo da identidade (Tavares et al., 2012). Além disso, há ausência de apoio social informal e formal para a família lidar com a situação de dependência e para reorganizar-se com vistas a investirem em projetos pessoais que foram abandonados por conta da situação crítica que se instaurou. Parece haver, na região em que habitam, escassez de atividades alternativas e de interação nas quais a família ou alguns membros pudessem se inserir, a fim de recriar laços sociais.

Em relação às variáveis de saúde, pode-se apontar como risco o fato de a família não acessar os serviços de saúde com frequência. $\mathrm{O}$ cuidado parece ser destinado apenas ao idoso, àquele que "está doente". A saúde ainda se configura no Brasil, apesar dos avanços, no modelo biomédico, isto é, centrada no atendimento clínico e físico individual, na doença e na falta de prevenção primária. Devido ao seu regimento pela ideologia neoliberal e privativista, a efetividade de ações no SUS fica dificultada, a exemplo da falta de visibilidade das políticas públicas da PNI nesse contexto (Brêtas, 2003).

\section{Política Nacional do Idoso (PNI)}

A PNI é a consolidação dos direitos garantidos pelos idosos. Portanto, ela própria contém fatores de risco e de proteção para essa família. Destacam-se como fatores de 
proteção, as legislações e políticas como o Estatuto do Idoso, que dá atenção a direitos fundamentais e necessidades da população idosa; o Pacto pela Vida, o SUS, que busca atenção integral e integrada ao idoso, e a criação do Conselho Nacional do Idoso, que prevê a participação ativa dos idosos na formulação das políticas, projetos e planos destinados a eles (Fernandez \& Santos, 2010). A crença de que o idoso deve manter-se na comunidade, vivendo de maneira saudável, força as políticas a se orientarem para o incentivo do convívio familiar e comunitário do idoso. A PNI reconhece e incentiva o cuidado informal e visa a que as equipes de saúde apoiem os cuidadores familiares, prevendo suporte emocional, de saúde e cognitivo - relacionado ao cuidado e à condição clínica - das equipes de saúde à família cuidadora. A própria legislação brasileira direcionada ao cuidado com o idoso está bem estruturada e consonante com outras legislações internacionais.

Entretanto, a PNI ainda é muito recente e existe, na cultura brasileira, a crença de que os familiares têm a obrigação de cuidar dos seus idosos, o que acaba por desresponsabilizar outros setores sociais. O desconhecimento das políticas e dos direitos por parte da família marca a sua apolitização e prejudica a busca por direitos garantidos na PNI. Ainda, apesar das mudanças na configuração populacional, há falta de recursos humanos qualificado. Um exemplo é a falta de disciplinas sobre geriatria e gerontologia nos cursos da área da saúde no ensino superior (Brêtas, 2003; Willig et al., 2012). Isso resulta em equipes que, embora realizem os cuidados, não têm conhecimentos atualizados sobre essa faixa etária e suas particularidades. Há um ageísmo presente em nossa cultura. Os valores da aposentadoria, geralmente insatisfatórios, não garantem, principalmente às camadas mais pobres, bem-estar social. Além disso, o processo de urbanização e as transformações sociais, econômicas e culturais vigentes no país contribuíram para o processo de enfraquecimento das relações comunitárias e familiares, tão importantes no cuidado com os idosos (Areosa \& Areosa, 2008).

\section{Considerações Finais}

Conclui-se que os fatores de risco e de proteção presentes nos diferentes sistemas impactam, em maior ou menor grau, o processo de resiliência dessa família. A mesma dispõe de mecanismos protetivos importantes, como os serviços de saúde e de pessoas que fornecem apoio emocional (mesossistema). Por outro lado, a família busca lidar com a situação do idoso de maneira "autossuficiente", ou seja, apesar de haver uma equipe de saúde presente e que oferta diferentes tipos de apoio, não os aceita, mesmo referindo sobrecarga na função desempenhada. Ainda, não sente que pode contar com o apoio da família extensa e não menciona nenhuma rede extrafamiliar, o que pode contribuir para o aumento da referida sobrecarga. Essa questão pode estar associada à crença de que o cuidado ainda é dever dos familiares mais próximos, já que não dispõem de condições para contratar um profissional especializado. Entretanto, o desconhecimento sobre os programas e a percepção de que os serviços não são acessíveis pode fomentar uma situação de vulnerabilidade e do adoecimento desses cuidadores, principalmente a filha. É interessante que as equipes de saúde que acompanham idosos acamados possam manter um olhar atento também para o cuidador, bem como auxiliar a família na busca de outros recursos. A articulação intersetorial pode auxiliar as famílias a reorganizarem-se "para fora", ou seja, a estabelecerem vínculos e buscarem apoio social.

As políticas públicas para idosos no Brasil, consolidadas na PNI, são inovadoras, consonantes com a legislação internacional e voltadas às novas configurações populacionais. No entanto, sua prática e sua efetivação encontram-se defasadas, o que se percebe no cotidiano dessa família (exossistema). Percebe-se, ainda, a falta da efetivação da PNI em relação à valorização do idoso e do cuidador nesse contexto, apesar do reconhecimento e incentivo ao cuidado informal. A "falta de espaço" na sociedade brasileira para os processos de envelhecimento - em especial o envelhecimento com dependência - prejudica a consolidação das políticas constantes na PNI e deixa a família sem opções de ocupação, lazer e apoio social. Verifica-se, neste caso, a necessidade de conscientização da família a respeito das políticas públicas existentes, para que garanta seus direitos, bem como da criação de programas específicos de apoio a familiares cuidadores. Além disso, no macrossistema, há o preconceito sobre o envelhecimento e sobre o adoecimento, que torna o idoso ainda mais vulnerável e isolado do sistema social.

Apesar desses fatores de risco e frente a esses desafios, a família tenta lidar com o idoso da melhor forma que consegue, sendo que o mesmo recebe os cuidados físicos necessários. Entretanto, seria mais fácil e prazeroso se efetivamente os fatores de proteção existentes nos sistemas ecológicos (meso-, exo- e macro-) fossem mais acessíveis ou percebidos como tal. Percebe-se que há ainda um caminho a ser percorridos para que todos os mecanismos de proteção potencialmente existentes nos contextos ecológicos estejam efetivamente atuantes.

Uma limitação deste estudo, por ser tratar de um caso único, é a impossibilidade de conhecer de forma abrangente o impacto das políticas públicas na população de idosos acamados no Brasil. E se, efetivamente, existe o acompanhamento por parte da rede de serviços de saúde e assistência públicos, bem como o acesso aos programas advindos dessa política. Entretanto, destaca-se, no presente estudo, a relevância de dar voz aos idosos com dependência, algo raro em estudos semelhantes, para melhor compreensão dos sentimentos e da situação familiar. $\mathrm{O}$ método utilizado neste estudo mostra a importância da análise das situações em um contexto, observando seus determinantes nos diferentes níveis e sistemas. Cada situação que envolva o idoso dependente exige uma articulação familiar diferenciada. Entretanto, a PNI e o Estatuto do idoso devem garantir o direito a uma intervenção efetiva e condizente com essa realidade familiar. 


\section{Referências}

Alvarenga, M.R.M., Oliveira, M.A.C., Domingues, M.A.R., Amendola, F., \& Faccenda, O. (2011). Rede de suporte social do idoso atendido por equipes de Saúde da Família. Ciência \& Saúde Coletiva, 16, 2603-11. doi 10.1590/S141381232011000500030

Areosa, S. V. C., \& Areosa, A. L. (2008). Envelhecimento e dependência: Desafios a serem enfrentados. Textos e Contextos, $7(1), 138-150$.

Augusto, F. M. F., da Silva, I. P., \& Ventura, M. M. (2009). Filhos cuidadores: Escolha, mudanças e desafios. Revista Kairós Gerontologia, 12(2), 103-118.

Barbosa, A. L., Oliveira, A. L., \& Figueiredo, D. (2012). Rede informal de apoio à pessoa idosa dependente: Motivações e fatores de stress em cuidadores primários e secundários. Revista Kairós Gerontologia, 15(1), 11-29.

Baptista, M. N. (2007). Inventário de Percepção de Suporte Familiar (IPSF): Estudo componencial em duas configurações. Psicologia Ciência e Profissão, 27(3), 496-509. doi. 10.1590/ S1414-98932007000300010.

BRASIL, Ministério do Desenvolvimento Social e Combate a Fome. (2010) Política Nacional do Idoso, PNI. Lei 8.842 de 04 de janeiro de 1994. Brasília, DF: Author.

Brêtas, A.C.P. (2003). Cuidadores de idosos e o Sistema Único de Saúde. Revista Brasileira de Enfermagem, 56 (3), 298-301. doi.10.1590/S0034-71672003000300016.

Brofenbrenner, U. (2011). Bioecologia do desenvolvimento humano: Tornando os seres humanos mais humanos. Porto Alegre: Artmed.

Camarano, A. A. (2006). Mecanismos de proteção social para a população idosa brasileira. Rio de Janeiro: IPEA.

Camarano, A. A., \& Pasinato, M. T. (2004). O envelhecimento populacional na agenda das políticas públicas. In A. A. Camarano (Ed.), Os Novos idosos brasileiros: Muito além dos $60 ?$ (pp. 253-292). Rio de Janeiro: IPEA.

Cassol, L., \& De Antoni, C. (2011). Família e abrigo como rede de apoio social e afetiva. In D. D. Dell'Aglio, S. H. Koller, \& M. A. M. Yunes (Eds.), Resiliência e Psicologia Positiva: Interfaces do risco à proteção (pp.173-201). São Paulo: Casa do Psicólogo.

De Antoni, C., Barone, L., \& Koller, S.H. (2011). Violência e pobreza: Um estudo sobre vulnerabilidade e resiliência familiar. In D. D. Dell'Aglio, S. H. Koller, \& M. A. M. Yunes (Eds.), Resiliência e Psicologia Positiva: Interfaces do risco à proteção (pp. 141-171). São Paulo: Casa do Psicólogo.

De Antoni, C., \& Koller, S.H. (2010). Uma família fisicamente violenta: Uma visão pela teoria bioecológica do desenvolvimento humano. Temas em Psicologia, 18(1), 17-30.

Diogo, M. J. D., Ceolim, M. F., \& Cintra, F. A. (2005). Orientações para idosas que cuidam de idosos no domicílio. Revista da Escola de Enfermagem da USP, 39(1), 97-102. doi.10.1590/ S0080-62342005000100013

Féres-Carneiro, T. (1997). Entrevista Familiar Estruturada - EFE: Um método de avaliação das relações familiares. Temas em Psicologia, 5(3), 63-94.

Fernandez, M. G. M., \& Santos, S.R. (2010). Políticas públicas e direitos do idoso: Desafios da agenda social do Brasil contemporâneo. Revista de Ciência Política, 34. Recuperado de http://www.achegas.net/numero/34/idoso_34.pdf.
Instituto Brasileiro de Geografia e Estatística. (2011) Resultados do Censo 2010. Brasília: IBGE. Recuperado de http://www. censo2010.ibge.gov.br/.

Koller, S. H., \& De Antoni, C. (2004). Violência familiar: Uma visão ecológica. In S. H. Koller (Ed.), Ecologia do desenvolvimento humano: Pesquisa e intervenção no Brasil (pp. 293-310). São Paulo: Casa do Psicólogo.

Lavinsky, A. E., \& Vieira, T. T. (2004). Processo de cuidar de idosos com acidente vascular encefálico: Sentimentos dos familiares envolvidos. Acta Scientiarum. Health Sciences 26(1), 41-45. doi: 10.4025

Mazza, M. M. P. R., \& Lefévre, F. (2005). Cuidar em família: Análise da representação social da relação do cuidador familiar com o idoso. Revista Brasileira de Crescimento e Desenvolvimento Humano, 15(1) 1-10.

Moreira, M. D., \& Caldas, C. C. (2007). A importância do cuidador no contexto da saúde do idoso. Escola Anna Nery Revista de Enfermagem, 11(3), 520-525. doi. 10.1590/S141481452007000300019.

Nardi, E. F. R., \& Oliveira, M. L. F. (2008). Conhecendo o apoio social ao cuidador familiar do idoso dependente. Revista Gaúcha de Enfermagem, 29(1), 47-53.

Neri, A. L., Yassuda, M. S., Araújo, L. F. de, Eulálio, M. do C., Cabral, B. E., Siqueira, M. E. C. de, Santos, G. A., \& Moura, J. G. A.. (2013). Metodologia e perfil sociodemográfico, cognitivo e de fragilidade de idosos comunitários de sete cidades brasileiras: Estudo FIBRA. Cadernos de Saúde Pública, 29(4), 778-792. doi.10.1590/S0102-311X2013000400015

Pereira, R. A., Santos, E. B., Fhon, J. R. S., Marques, S., \& Rodrigues, R.A.P. (2013). Sobrecarga dos cuidadores de idosos com acidente vascular cerebral. Revista da Escola de Enfermagem da USP, 47(1), 185-192. doi. 10.1590/S008062342013000100023

Poletto, M., \& Koller, S. H. (2011). Resiliência: Uma perspectiva conceitual e histórica. In D. D. Dell'Aglio, S. H. Koller, \& M. A. M. Yunes (Eds.), Resiliência e psicologia positiva: Interfaces do risco à proteção. (pp. 19-44). São Paulo: Casa do Psicólogo.

Rodrigues, N. C. (2001). Política Nacional do Idoso - Retrospectiva histórica. Estudos Interdisciplinares do Envelhecimento, 3, 149-158.

Sebastião, C., \& Albuquerque, C. (2011). Envelhecimento e dependência. Estudo sobre os impactes da dependência de um membro idoso na família e no cuidador principal. Revista Kairós Gerontologia, 14(4), 25-49

Silva, M. R. S., Lacharité, C., Silva, P. A., Lunardi, V. L., \& Lunardi Filho, W. D. (2009) Processos que sustentam a resiliência familiar: Um estudo de caso. Texto \& Contexto Enfermagem, 18(1), 92-99. doi. 10.1590/S0104-07072009000100011.

Silveira, T. M., Caldas, C. P., \& Féres-Carneiro, T. (2006) Cuidando de idosos altamente dependentes na comunidade: Um estudo sobre cuidadores familiares principais. Cadernos de Saúde Pública, 22(8), 1629-1638. doi:10.1590/S0102311 X2006000800011.

Schuck, L. M., \& De Antoni, C. (2014). Resiliência e vulnerabilidade no cuidado com o idoso dependente: Um estudo de caso. Temas de psicologia, 22(4) 941-951. doi.10.9788/TP2014.4-20

Tavares, K. O., Scalco, J. C., Vieira, L., Silva, J. R., \& Bastos, C. C. C. B. (2012). Envelhecer, adoecer e tornar-se dependente: A visão do idoso. Revista Kairós Gerontologia, 15(3), 105-118. 
Teodoro, M. (2012). Alguns instrumentos para avaliação familiar no Brasil. In M. Teodoro \& M. N. Baptista (Eds.), Psicologia de família: Teoria, avaliação e intervenção (pp.168-175). Porto Alegre: Artmed.

Tier, C. C., Souza, M. B., Soares, M. C. F., Santos, S. S. C., Baisch, A. L. M., \& Cestari, M. A. C. (2006). Política de saúde do idoso: Iniciativas identificadas no município de Rio GrandeRS. Cogitare Enfermagem, 11(1), 39-43. doi: 10.5380

Vieira, C.P.B., \& Fialho, A.V.M. (2010). Perfil de cuidadores familiares de idosos com Acidente Vascular Cerebral Isquêmico. Revista RENE, 11(2), 161-169

Vieira, L., Nobre, J. R. S., Bastos, C. C. B. C., \& Tavares, K. O. (2012). Cuidar de um familiar idoso dependente no domicílio: Reflexões para os profissionais da saúde. Revista Brasileira de Geriatria e Gerontologia, 15(2), 255-264. doi10.1590/S1809-98232012000200008.
Willig, M. H., Lenardt, M. H., \& Méier, M. J. (2012). A trajetória das políticas públicas do idoso no Brasil: Breve análise. Cogitare Enfermagem, 17(3), 574-577. doi.10.5380.

Recebido em 30/12/2014

Revisado em 25/05/2016

Aceito em 19/07/2016 